\title{
REVIEW
}

\section{Portopulmonary hypertension and hepatopulmonary syndrome: a clinician-oriented overview}

\author{
Mateo Porres-Aguilar*, Jose T. Altamirano", Aldo Torre-Delgadillo", \\ Michael R. Charlton ${ }^{+}$and Andres Duarte-Rojo ${ }^{\S}$
}

ABSTRACT: Liver disease and portal hypertension can be associated with pulmonary vascular complications, including portopulmonary hypertension (POPH), characterised by an elevated mean pulmonary artery pressure secondary to an increased pulmonary vascular resistance, and hepatopulmonary syndrome (HPS), characterised by hypoxaemia due to pulmonary vasodilatation and shunting.

Although clear diagnostic guidelines exist for both conditions on the basis of echocardiography, right heart catheterisation and arterial blood gases, there is considerable variation between centres regarding diagnosis and management of these conditions. Awareness of evaluation and management algorithms for POPH and HPS are critical for optimisation of outcomes in patients with these conditions.

Key aspects of management of POPH and HPS include identification of patients likely to benefit from liver transplantation (LTx) and management before and after LTx. Although both disorders may improve after LTx, severe forms of POPH represent a contraindication to LTx.

Novel approaches to the treatment of POPH and HPS offer new management options that may expand the pool of transplantable patients and improve overall outcomes.

KEYWORDS: Cirrhosis, hepatopulmonary syndrome, liver transplantation, portal hypertension, portopulmonary hypertension, pulmonary hypertension

$\mathbf{T}$ he liver is a unique organ as it is connected in series between the portal system and the lung. In patients with liver disease and/or portal hypertension, constituents of venous blood arising from both the liver and portal system can directly injure the pulmonary vascular endothelium. Pulmonary vascular complications in liver disease/portal hypertension have long been documented in the form of portopulmonary hypertension (POPH) and hepatopulmonary syndrome (HPS), producing important morbidity and mortality, including the setting of liver transplantation (LTx). There has been increasing recognition of the importance of these pulmonary vascular complications of liver disease, with increasing recognition that these complications influence survival before, during and after LTx. This review will discuss POPH and HPS from a practical standpoint, with a goal of assisting clinicians in the care of affected patients.

\section{PORTOPULMONARY HYPERTENSION}

POPH is best defined as pulmonary arterial hypertension (PAH) associated with portal hypertension, whether or not portal hypertension is secondary to an underlying liver disease [1-3]. Initially categorised under the term secondary $\mathrm{PAH}$, the World Health Organization now recognises the diagnosis of POPH as a distinct entity [4, 5]. Current criteria include: 1) the presence of portal hypertension (either inferred from the presence of splenomegaly, thrombocytopenia, portosystemic shunts, oesophageal varices or portal vein abnormalities, or confirmed by haemodynamic measurements), but not necessarily the presence of cirrhosis; and 2) haemodynamic measurements from right heart catheterisation (RHC) including mean pulmonary artery pressure (mean $P$ pa) $>25$ $\mathrm{mmHg}$ at rest, mean pulmonary capillary wedge pressure (mean $\mathrm{Ppcw}$ ) $<15 \mathrm{mmHg}$, and pulmonary vascular resistance $(\mathrm{PVR})>240 \mathrm{dyn} \cdot \mathrm{s} \cdot \mathrm{cm}^{-5}$ or

\section{AFFILIATIONS}

${ }^{*}$ Dept of Internal Medicine, Division of Hospital Medicine, Texas Tech University Health Sciences Center, Paul L. Foster School of Medicine, El Paso, TX,

${ }^{+}$Division of Gastroenterology and Hepatology, Mayo Clinic, Rochester, $\mathrm{MN}$,

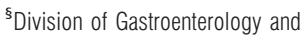
Hepatology, University of Arkansas for Medical Sciences, Little Rock, AR, USA.

\#Liver Unit, Hospital Clinic, Institut d'Investigacions Biomediques August Pi I Sunyer, Barcelona, Spain. "Liver Unit, National Institute of Medical Sciences and Nutrition Salvador Zubiran, Mexico City, Mexico.

CORRESPONDENCE

A. Duarte-Rojo

Division of Gastroenterology and Hepatology

University of Arkansas for Medical Sciences

4301 W. Markham St. \#567

Shorey S8/68

Little Rock

AR

USA

E-mail: ADuarteRojo@uams.edu

Received:

Sept 172011

Accepted after revision:

Dec 172011

PROVENANCE

Submitted article, peer reviewed.

European Respiratory Review Print ISSN 0905-9180 Online ISSN 1600-0617 
$>3$ Wood units: PVR $=[($ mean $P$ pa-mean $P$ pcw $) /$ cardiac output] $\times 80[1]$.

\section{Epidemiology and risk factors}

The incidence and prevalence of POPH is not well defined. However, in the early 1980s, a histopathological post mortem study of $>17,000$ patients showed vasculopathic changes of $\mathrm{PAH}$ to be more frequent in patients with concomitant portal hypertension $(0.73 \%)$ than in those without it $(0.13 \%)$ [6]. More recent prospective studies, particularly in tertiary centres evaluating patients for LTx, have shown a higher prevalence of $6.3 \%$ [7] and $8.5 \%$ [8]. Identification of POPH is made at an average of 4-7 yrs after the diagnosis of portal hypertension, and it usually presents during the fifth decade of life, as compared with the third and fourth decade for idiopathic PAH [5]. In a recent case-control study from seven tertiary-care LTx centres, POPH was found to be associated with female sex and underlying autoimmune liver disease, whereas hepatitis $C$ virus infection was negatively associated with POPH [7]. Severity of liver disease, as measured by the Child-Pugh and Model of End-stage Liver Disease (MELD) scores, was not associated with the presence of POPH [7]. The severity of $\mathrm{POPH}$ has not been found to correlate with severity of liver disease [9]. Recently, the REVEAL registry, a multicentre, observational study, designed to study longitudinal and clinical course and management of 3,000 PAH patients, reported a frequency of POPH of 5.1\% [10].

\section{Pathophysiology}

The pathogenesis of POPH is not completely understood. Histopathologically, POPH is indistinct from idiopathic PAH. Pulmonary vascular changes include intimal fibrosis, hypertrophy of the smooth muscle cells and fibroblasts, in situ thrombosis, and plexiform lesions resulting from intraluminal endothelialisation or micro-aneurysms within pulmonary arterioles [11, 12]. A popular proposed mechanism for POPH development suggests that the increased blood flow (high cardiac output) in chronic liver disease causes pulmonary vascular wall shear stress, which can trigger the dysregulation of numerous vasoactive, proliferative and angiogenic mediators eventually leading to the characteristic arteriopathic changes mentioned above [12]. The portosystemic shunts and decreased phagocytic capacity of the liver that occur in these patients allow circulating bacteria and bacterial endotoxins from the gastrointestinal tract to enter the pulmonary circulation. As pulmonary phagocytosis has been demonstrated in cirrhosis, it is suggested that the recruitment of interstitial macrophages might also contribute to the development of POPH [13]. Furthermore, the presence of portosystemic shunts may allow the shunting of vasoactive substances from the splanchnic to the pulmonary circulation, causing deleterious effects in the pulmonary vasculature [1-3].

Endothelin (ET)-1 is thought to play a major role in the pathophysiology of POPH. ET-1 is a potent pulmonary and systemic vasoconstrictor, as well as vasoproliferative molecule, increased levels of which have been observed among patients with liver disease, probably as a result of increased wall shear stress during hyperdynamic circulation [13]. The biological effects of ET-1 are mediated by two distinct receptors subtypes, ETA and ЕTв. In the pulmonary vasculature, activation of ETA induces vasoconstriction, smooth muscle cell proliferation and intimal fibrotic changes. Although ETB receptors normally mediate peripheral vasodilation, overexpression and dysregulated signalling of ЕTв in the pulmonary vasculature may contribute to increased pulmonary vasomotor tone and remodelling has been observed in POPH [14]. Upregulation of several additional neurohumoral mediators, such as thromboxane-B1, interleukin-6 and serotonin have also been implicated in the pathophysiology of POPH [11, 15]. Early studies suggested a causal role for serotonin in $\mathrm{POPH}$ as a promoter of vasoconstriction and vascular smooth muscle mitogenesis [16], although genetic polymorphisms in the serotonin transporter are not predictive of the development of POPH [17, 18]. Finally, vasodilating mediators, such as nitric oxide $(\mathrm{NO})$ and prostaglandin $\mathrm{I}_{2}$ (prostacyclin), may be decreased in $\mathrm{POPH}$, facilitating vascular remodelling and vasoproliferative response. Prostacyclin synthase, the enzyme responsible for prostacyclin synthesis, has been demonstrated to be deficient in the pulmonary endothelium of patients with POPH [19].

\section{Clinical manifestations}

Clinicians must maintain a high index of suspicion when evaluating patients with liver disease, since POPH itself typically produces no symptoms or only has symptoms related to the underlying cirrhosis or portal hypertension. Moreover, primary cardiopulmonary disorders (e.g. cardiac failure, obstructive or restrictive lung disease) can also be present in patients with cirrhosis, further complicating the clinical picture.

Dyspnoea on exertion is the most common presentation complaint, but it is important to acknowledge that this symptom is frequently related to other conditions such as refractory ascites with mechanical thoracic impairment, hepatic hydrothorax, anaemia and sarcopenia/deconditioning [20,21]. Other common symptoms include fatigue, generalised weakness, lightheadedness and orthopnoea. In advanced stages of $\mathrm{POPH}$, symptoms like oppressive chest discomfort, dyspnoea while at rest, syncope and haemoptysis can occur.

Physical examination may reveal elevated jugular venous pressure, an accentuated pulmonic component (P2) of the second heart sound, a holosystolic murmur consistent either with tricuspid regurgitation or pulmonic insufficiency (GrahamSteele murmur), as well as a right ventricular heave with signs of right heart failure (third or fourth heart sounds). A pulsatile liver during abdominal examination and dependent lower extremity oedema out of proportion to ascites may also signal right ventricular dysfunction. Physical stigmata of cirrhosis and portal hypertension, such as splenomegaly, ascites, spider angiomata, scleral icterus, jaundice, palmar erythema, gynecomastia and asterixis may also be observed.

\section{Diagnostic evaluation and classification}

A detailed diagnostic evaluation to exclude other potential causes of dyspnoea, particularly other forms of pulmonary hypertension $(\mathrm{PH})$, is important in making the diagnosis of $\mathrm{POPH}$. The differential diagnosis includes idiopathic $\mathrm{PAH}, \mathrm{PH}$ associated with collagen vascular disease, HIV infection, chronic thromboembolic disease, and $\mathrm{PH}$ resulting from left heart or chronic lung diseases $[4,5]$. 
General cardiopulmonary screening tests, such as electrocardiography, may reveal right axis deviation, right atrial and ventricular enlargement and right ventricular strain pattern as well as complete right bundle branch block. Chest radiographs may show an enlargement of the right-sided chambers, as well as dilatation of the pulmonary arteries. Pulmonary function tests may identify a decreased diffusing capacity, and the ventilation/perfusion lung scan is usually normal, as compared when segmental perfusion defects are present (a "mosaic" pattern) suggesting chronic thromboembolic PH. Arterial blood gases (ABGs) may show an increased alveolar-arterial oxygen tension difference $\left(\mathrm{PA}-\mathrm{a}, \mathrm{O}_{2}\right)$, mild-to-moderate hypoxaemia and decreased arterial carbon dioxide tension $(<30 \mathrm{mmHg})[22,23]$.

The single most important test to screen for POPH is the twodimensional transthoracic echocardiogram (TTE) [24-26]. The European Society of Cardiology guidelines recommend TTE screening in all symptomatic patients with liver disease, and routinely as part of LTx evaluation due to the high morbidity and mortality risk associated with performing LTx in patients with POPH [26]. TTE is pivotal in patients with clinical suspicion of $\mathrm{POPH}$ and also to initially assess appropriate candidacy for LTx, as endorsed by the American Association for the Study of Liver Diseases [25]. Because of the high mortality associated with attempting to perform LTx in patients with severe $\mathrm{POPH}$, which is related to haemodynamic instability, screening for POPH should occur before the LTx procedure is planned [27]. Using TTE, the right ventricular systolic pressure (RVSP) can be estimated from the peak tricuspid regurgitant velocity by using the modified Bernoulli equation. In spite of the poor agreement between TTE and RHC parameters [9], LTx programmes have successfully used RVSP to identify patients needing RHC. However, different cut-off values are used according to the clinical need. For example, the Mayo Clinic (Rochester, MN, USA) uses an RVSP cut-off of $50 \mathrm{mmHg}$ to identify patients with moderate-tosevere POPH with positive and negative predictive values of $74 \%$ and $97 \%$, respectively [28]. This approach has been validated on the basis of accumulating prospective clinical experience with over 900 LTx patients [9]. COLLE et al. [24] reported on a threshold cut-off value of $30 \mathrm{mmHg}$ for diagnosing all degrees of $\mathrm{POPH}$ having positive and negative predictive values of $59 \%$ and $100 \%$, respectively, among 165 patients submitted to successive TTE and cardiac catheterisation in LTx candidates. Thus, an RVSP $<30 \mathrm{mmHg}$ can be used to rule out $\mathrm{POPH}$, whereas an $\mathrm{RVSP} \geqslant 50 \mathrm{mmHg}$ predicts moderate-to-severe $\mathrm{POPH}$ in three out of four patients. Whether patients with an RVSP between 30 and $50 \mathrm{mmHg}$ need to undergo RHC should be determined on an individual basis. TTE yields some other benefits, as it may also show pulmonic insufficiency, right ventricular hypertrophy, dilatation and dysfunction, as well as right atrial enlargement, that could be indirect signs of significant PAH. Paradoxical septal movement is also common [1, 2].

TTE cannot fully discriminate between increased PVR due to true vaso-oclussive arteriopathy or due to an increased pulmonary flow phenomenon (hyperdynamic state, e.g. due to fluid overload, with normal/low PVR). Therefore, RHC represents the gold standard for the diagnosis of POPH. Patients should not be fluid overloaded at the time of RHC. Using this technique mean $P$ pa, mean $P$ pcw and cardiac output, as well as PVR, can be accurately obtained in order to meet the currently proposed POPH definition. Furthermore, POPH can be further staged according to mean $P$ pa as shown in table 1 [27, 29].

To properly interpret the haemodynamic parameters associated with $\mathrm{POPH}$, it is very important to be familiar with common changes that occur in patients with end-stage liver disease: $\sim 30$ to $50 \%$ have low systemic vascular resistance and high cardiac output. In this group, the mean $P$ pa may be elevated solely as a consequence of increased cardiac output, giving low values of PVR [29]. These low PVR values that characterise the hyperdynamic state of end-stage liver disease have led to some authors proposing that a PVR cut-off value of $>120 \mathrm{dyn} \cdot \mathrm{s} \cdot \mathrm{cm}^{-5}$ be used to define POPH [29]. Unfortunately, there are no epidemiological data to support the validity of one definition over the other. Another haemodynamic criterion proposed for diagnosing POPH is the transpulmonary gradient (TPG). This parameter correlates with PVR and identifies resistance to flow in patients with an elevated mean $P$ pcw: TPG $=$ mean $P$ pa-mean $P$ pcw. Thus, a TPG $>12 \mathrm{mmHg}$ is highly indicative of increased PVR and should be a key diagnostic feature to define a true increase in PVR in patients with both elevated mean Ppa and mean Ppcw $[9,29,30]$.

\section{Prognosis and clinical course}

POPH causes progressive stress to the right ventricle, leading to right ventricular dysfunction, progressive chronic cor pulmonale and eventually death [1]. The degree of right ventricular dysfunction correlates highly with survival and mortality in patients with POPH. An earlier study by RoBALINO et al. [31] showed a poor 1-yr survival of $<40 \%$. LE PAVEC et al. [32] demonstrated that survival is at least as good when compared with idiopathic PAH with overall survival rates at 1, 3 and $5 \mathrm{yrs}$ of $88 \%, 75 \%$ and $68 \%$, respectively. The study of ROBALINO et al. [31] was performed before the era of PAHspecific therapy, contrasting with the report of LE PAVEC et al. [32] where $29 \%$ of patients, the most gravely ill, received this treatment. Not surprisingly, LE PAVEC et al. [32] found that prognosis of $\mathrm{POPH}$ was related to cardiac index and to the severity of liver disease, but even for patients with the worst outcome (i.e. Child-Pugh class C) the 5-yr survival rate was $58 \%$. An impact of PAH-specific therapies on survival could not be identified in their multivariable analysis [32]. However, a retrospective study provided gross estimates of 5-yr

\begin{tabular}{|c|c|c|c|}
\hline \multirow[t]{2}{*}{ TABLE 1} & \multicolumn{3}{|c|}{$\begin{array}{l}\text { Diagnostic criteria and staging for portopulmonary } \\
\text { hypertension }\end{array}$} \\
\hline & Mean Ppa mmHg & Mean $P_{p c w}{ }^{\#}$ mmHg & PVR dyn $\cdot \mathbf{s} \cdot \mathrm{cm}^{-5}$ \\
\hline Mild & $>25$ to $<35$ & $<15$ & $>240$ \\
\hline Moderate & $\geqslant 35$ to $<45$ & $<15$ & $>240$ \\
\hline Severe & $\geqslant 45$ & $<15$ & $>240$ \\
\hline \multicolumn{4}{|c|}{$\begin{array}{l}\text { Ppa: pulmonary artery pressure; Ppcw: pulmonary capillary wedge pressure; } \\
\text { PVR: pulmonary vascular resistance. }{ }^{\#:} \text { a transpulmonary pressure gradient } \\
>12 \mathrm{mmHg} \text { could substitute this criterion in patients with an elevated mean } \\
\text { Ppcw but fulfilling other criteria; }{ }^{\ominus}: \text { a PVR }>120 \mathrm{dyn} \cdot \mathrm{s} \cdot \mathrm{cm}^{-5} \text { is recommended by } \\
\text { some authors. }\end{array}$} \\
\hline
\end{tabular}


mortality in subgroups of patients receiving no treatment (natural history), medical therapy (PAH-specific agents) or LTx (plus PAH-specific agents), as being 86\% (54\% dying within the first year of diagnosis), 55\% and 33\%, respectively [33].

\section{Treatment}

The general goals of therapy for POPH are to provide symptomatic relief, improve quality of life and exercise capacity, and to facilitate successful LTx. Despite considerable overlap in the general therapeutic approach in patients with diverse forms of $\mathrm{PAH}$, such as idiopathic $\mathrm{PAH}$, important distinctions in the POPH management should be made. The use of calcium channel blockers is generally recommended for the minority of idiopathic PAH patients that have shown a sustained acute vasodilator challenge response during RHC [34]. However, responders to calcium channel blockers are exceptional in POPH [35] and, in general, they are contraindicated as they can produce mesenteric vasodilation that can worsen portal hypertension [36]. Despite the strong evidence and wide use of $\beta$ blockers to aid in primary and secondary prophylaxis for variceal gastrointestinal bleeding in the setting of portal hypertension, it has been demonstrated that in $\mathrm{POPH}$ their use has been associated with deterioration of exercise capacity and pulmonary haemodynamics, due to their negative inotropic and chronotropic effects [37]. Oral anticoagulation is regularly recommended for many forms of $\mathrm{PAH}$, although it is traditionally not recommended for patients with $\mathrm{POPH}$ due to the increased risk of gastrointestinal haemorrhage in this population $[1,2]$. Diuretics such as furosemide and spironolactone may offer symptomatic relief in patients with right heart failure due to PAH and liver cirrhosis and have an important role in POPH patients with volume overload and fluid retention. Close monitoring is required, however, since diuretics can reduce cardiac output by decreasing right ventricular preload, facilitating renal failure and systemic hypoperfusion. Mild-tomoderate hypoxaemia is a common feature in POPH. Since hypoxaemia can promote pulmonary vasoconstriction, supplemental oxygen should be considered for $\mathrm{POPH}$ when the arterial oxygen tension $\left(\mathrm{Pa}_{\mathrm{a}} \mathrm{O}_{2}\right)$ reaches $<60 \mathrm{mmHg}[1,2]$.

\section{PAH-specific therapies}

During the past two decades, significant advances have been made by developing vasodilating and antiproliferative therapeutic agents for patients with diverse forms of PAH. Prostacyclin analogues (PAs), endothelin receptor antagonists (ETAs) and phosphodiesterase-5 inhibitors have changed the natural history of patients with PAH. However, most of the evidence emerged from the subgroup of patients with idiopathic $\mathrm{PAH}$ and $\mathrm{PH}$ associated with connective tissue disorders, since POPH patients were excluded earlier from randomised clinical trials [38]. PAH-specific treatment has been extrapolated to $\mathrm{POPH}$ and their effectiveness documented in some case reports and case series, but there is a lack of data regarding overall efficacy.

Epoprostenol is an intravenous PA, and is the only drug that has proven survival benefit in patients with $\mathrm{PAH}$, as well as being the best studied drug in POPH [39]. Epoprostenol is not an easy therapy to administer due to its continuous intravenous complex pump delivery system that requires permanent central venous access, constant maintenance and monitoring by an expert nurse, with the risk of life-threating complications, including rebound pulmonary vasoconstriction if the pump fails. In one of the largest series, epoprostenol was shown to improve pulmonary haemodynamics and cardiac output in both the acute and long-term setting [39]. These findings have been reproduced by other authors $[40,41]$. Other PAs have also been evaluated in the management of POPH. Intravenous iloprost significantly improved pulmonary haemodynamics over a 12-month period of follow-up in a single patient with severe POPH [42]. Another patient with severe POPH was successfully bridged to LTx with continuous intravenous iloprost and was without PAH after 2 yrs of follow-up [43]. Recently, Melgosa et al. [44] showed both acute and sustained haemodynamic and clinical improvement over a period of 12 months in POPH patients receiving inhaled iloprost. Generally, PAs are well tolerated with minimal adverse effects that include flushing, headaches and cough.

It has been demonstrated that ET-1 levels are elevated in the setting of POPH $[13,14]$, raising the possibility of oral ETAs in the treatment of POPH. Bosentan, a dual non-selective ETA has the advantage of being administered orally. HoEPER et al. [45] showed that therapy with bosentan in 11 patients with ChildPugh class A cirrhosis was associated with improvement in symptoms and exercise capacity, as well as in haemodynamics, being well tolerated and without evidence of drug-related liver injury [45]. The selective ETA receptor antagonist ambrisentan, requiring only once daily dosing, was recently reported in a study of 13 patients with POPH [46]. Significant haemodynamic improvements were seen with minimal drug interactions, but also a risk of clinically significant liver toxicity.

The oral phosphodiesterase inhibitors sildenafil and tadalafil were recently approved for the therapy of PAH [47, 48], constituting another attractive therapeutic alternative. REICHENBERGER et al. [49] studied 14 patients with moderate-to-severe POPH treated with oral sildenafil for up to 12 months. Sildenafil provided therapeutic benefits in pulmonary haemodynamics during the first 3 months, although this was not sustained after 12 months, despite continuous improvement in exercise capacity and functional class [49]. It is likely that sildenafil is not sufficient as monotherapy in severe POPH and that patients with severe POPH may benefit from combination therapy with different drug classes in order to enhance vasodilating and antiproliferative mechanisms [50].

\section{Liver transplantation}

LTx in POPH is performed to treat the underlying portal hypertension/liver disease, and POPH confers a high risk of cardiopulmonary-related morbidity and mortality from fulminant right ventricular failure among patients who undergo LTx $[1,51]$. A mean $P$ pa $>35 \mathrm{mmHg}$ and $/$ or a PVR $>250 \mathrm{dyn} \cdot \mathrm{s} \cdot \mathrm{cm}^{-5}$ are both associated with an LTx mortality of $\sim 50 \%$ [52]. Patients with a mean $P$ pa of $>35-50 \mathrm{mmHg}$ and a PVR $<250 \mathrm{dyn} \cdot \mathrm{s} \cdot \mathrm{cm}^{-5}$ have been observed to have acceptable post-transplant outcomes (notably, this study used 120 instead of $240 \mathrm{dyn} \cdot \mathrm{s} \cdot \mathrm{cm}^{-5}$ to define $\mathrm{POPH})$. Based on the preponderance of reported experience, a mean $P$ pa $\geqslant 50 \mathrm{mmHg}$ and/or a PVR of $>250$ dyn $\cdot \mathrm{s} \cdot \mathrm{cm}^{-5}$ should be considered to be a contraindication to LTx. Our understanding of the impact of PAH-specific therapies that produce improvements in cardiopulmonary haemodynamics to a mean $P$ pa $<35 \mathrm{mmHg}$ and a PVR $<250 \mathrm{dyn} \cdot \mathrm{s} \cdot \mathrm{cm}^{-5}$ 
on post-transplant outcomes is still evolving. Patients who achieve improvements in mean Ppa and PVR to these levels on therapy should be considered potential candidates for LTx $[29,30,40,41]$.

Current liver allocation policies in the USA allow appealing for MELD exception points in patients with an initial mean $P$ pa $>35 \mathrm{mmHg}$ who maintain a favourable pulmonary profile (i.e. mean $P$ pa $<35 \mathrm{mmHg}$ and PVR $<400 \mathrm{dyn} \cdot \mathrm{s} \cdot \mathrm{cm}^{-5}$ ) and a satisfactory right ventricular function while on PAH-specific treatment. This policy has the intention to expedite LTx before definite contraindications occur, given that survival has not been shown to be inferior in this subset of $\mathrm{POPH}$ patients, when compared to all LTx patients [53, 54]. If the decision is made to proceed with LTx in a patient with significant POPH in the clinical setting of a pharmacological response, transoesophageal echocardiography to monitor for right ventricular failure, veno-venous bypass to prevent right ventricular overload after reperfusion, and the potential use of inhaled NO therapy or inhaled epoprostenol to lower mean P pa and PVR may be considered as intraoperative strategies to minimise the risk of fulminant right ventricular failure. Patients with POPH should ideally be treated at LTx referral centres with a multidisciplinary team (anaesthesiologists, cardiologists, pulmonologists and hepatologists) experienced in the perioperative treatment of POPH [55]. Whether POPH improves after LTx is a matter of debate. Initial experience indicated that post-transplant improvement in "POPH" was limited to patients with $\mathrm{PH}$ secondary to an increased cardiac output (elevated mean $P$ pa but PVR $<240$ dyn $\cdot s \cdot \mathrm{cm}^{-5}$ ). Accumulating evidence from different transplant centres is now manifesting post-transplant improvement in selected POPH patients, some of them being able to wean-off their PAH-specific therapy a few months after LTx (probably $\sim 50 \%$ of those surviving the early months after LTx) [33, 40, 54,56]. Although these are encouraging results, evidence derives from retrospective analyses of transplant databases or case series. Thereby, the percentage of patients improving is not so clear to date and there are no known predictors to better select them. It must be accounted that there are also reports on post-transplant progression of POPH [57]. With current evidence, LTx should not be viewed as a healing measure for $\mathrm{POPH}$, and $\mathrm{PAH}$-specific therapies should continue during the early post-transplant period. Periodic haemodynamic surveillance is mandatory to allow proper adjustment of treatment and identify patients who can be weaned off PAHspecific therapy.

\section{HEPATOPULMONARY SYNDROME}

HPS is characterised by the triad of arterial deoxygenation (a widened $\mathrm{PA}-\mathrm{a}, \mathrm{O}_{2}$ with or without hypoxaemia), intrapulmonary vascular dilatation and liver disease [58,59]. HPS can occur with any degree of liver disease, ranging from well-compensated chronic liver disease without cirrhosis to noncirrhotic portal hypertension and cirrhosis. HPS has also been described in patients with acute liver failure [29].

\section{Epidemiology and risk factors}

The reported prevalence of HPS varies depending on the population studied and the criteria used to define arterial deoxygenation and intrapulmonary vascular dilatation. HPS has been reported in $10-30 \%$ of patients referred for LTx evaluation
$[60,61]$, but in only $1 \%$ of patients with chronic liver disease in the non-transplant setting [62]. The presence of either intrapulmonary shunts or oxygenation abnormalities are more common, occurring in 25-65\% of patients awaiting LTx and in $5 \%$ of patients in the non-transplant setting [61-64]. HPS is usually diagnosed during the sixth decade of life and there is no specific association with sex or aetiology of liver disease. The majority of studies in patients with cirrhosis have not found an association between HPS and severity of liver disease, as measured by Child-Pugh and MELD scores [61, 65, 66]. However, there are reports of more advanced liver failure in patients with HPS, particularly in those presenting with hypoxaemia $[60,67,68]$.

\section{Pathophysiology}

The hallmark of HPS is intrapulmonary vasodilatation. The most remarkable anatomic abnormality is dilatation at both the pre-capillary and capillary level of the pulmonary circulation (50-80 $\mu \mathrm{m}$; normal range is $8-15 \mu \mathrm{m}$ ), especially in the lower lobes. Less frequently, discrete arteriovenous anastomoses unrelated to the alveolar-capillary unit may be identified, as well as portopulmonary anastomoses. The consequence of the intrapulmonary vasodilatation is arterial deoxygenation by three mechanisms: ventilation/perfusion $\left(V^{\prime} / Q^{\prime}\right)$ mismatch, intrapulmonary shunting, and limitation of oxygen diffusion. The main mechanism seems to be related to a low $V^{\prime} / Q^{\prime}$, a hypothesis strongly supported by improvement of $\mathrm{Pa}, \mathrm{O}_{2}$ while breathing $100 \% \mathrm{O}_{2}$ in the majority of affected patients. The hyperdynamic circulation present in patients with cirrhosis causes a decrease in the transit time of erythrocytes through the alveolar-capillary unit, further compromising oxygen diffusion. All three mechanisms contribute to passing of mixed venous blood to the systemic circulation [69].

The aetiology of intrapulmonary vascular dilatations is thought to relate to an increase in pulmonary $\mathrm{NO}$, by means of both endothelial and inducible NO synthase (eNOS and iNOS, respectively). The link between liver failure/portal hypertension and increased NO is incompletely understood but seems to be related to an increase in hepatic production of the vasoconstrictor ET-1, which stimulates the production of the ETB receptor at the level of the pulmonary microcirculation, with subsequent increase in eNOS activity causing vasodilatation. A local increase in pro-inflammatory mediators and pulmonary intravascular sequestration of macrophages leading to an increase in iNOS activity and NO production has also been described [70]. This may be caused by bacterial translocation and systemic endotoxaemia and, presumably, it is largely mediated by tumour necrosis factor $\alpha$ [71, 72]. Other mechanisms/associations identified to date through human or experimental studies include increased angiogenesis through upregulation of the vascular endothelial growth factor, increased carbon monoxide production through haem oxygenase, and increased levels of oestrogen and progesterone. A recent study of genetic risk factors showed an association of HPS with genes related to vascular growth and development, as well as oestrogen action, but failed to demonstrate association with NO synthase, ETB and haem oxygenase [73]. Experimental data has also supported a relevant role for exacerbated angiogenesis in the pathogenesis of HPS [74]. 


\section{Clinical manifestations}

Dyspnoea, digital clubbing, cyanosis and spider angiomas are characteristic features in patients with HPS. Dyspnoea on exertion may lack specificity as it does not occur more frequently in the setting of HPS [61], probably being confounded by physical deconditioning and fatigue, which are very common among patients with cirrhosis. Platypnoea and orthodeoxia, the increase in dyspnoea or deoxygenation while in the standing position, are classically described in HPS. These occur as the change from supine to standing position exacerbate the $V^{\prime} / Q^{\prime}$ mismatch through decreased perfusion of the highly ventilated lung apices, and the opposite effect in the bases, driven by changes in hydrostatic pressure and the predominance of pulmonary dilatations in the lung bases. However, these are not pathognomonic features and actually orthopnea seems to be a more frequent manifestation in HPS [65]. As in $\mathrm{POPH}$, other physical stigmata of cirrhosis and portal hypertension can be seen in patients with HPS.

\section{Diagnostic evaluation and classification}

Whenever a patient with liver disease presents with clinical manifestations of HPS, investigations assessing arterial oxygenation and pulmonary dilatation are mandatory. Evidence of concomitant lung diseases should also be investigated by pulmonary function tests and imaging, and it is important to consider that HPS can coexist with other pulmonary or cardiac diseases exacerbating symptoms and hypoxaemia [75]. As part of the LTx evaluation, most centres will perform pulmonary and cardiac studies as a matter of routine practice or on the basis of the clinical context (e.g. history of smoking, $\alpha_{1}$-antitrypsin deficiency, ischaemic heart disease).

Chest radiographs are usually normal in patients with HPS but can manifest an increased interstitial pattern in the bases, an effect usually caused by arteriovenous shunts in severe HPS. High-resolution computed tomography can identify dilatation of the peripheral pulmonary vessels in the lung bases at early stages of HPS, although the clinical usefulness of this finding is uncertain at the present time [76]. Paradoxical embolism can occur and must be considered in any patient with HPS, given a relatively high prevalence of cerebrovascular disease, presenting with a stroke [77]. Consistent with the decreased diffusion capacity of oxygen observed in HPS, the diffusing capacity of the lung for carbon monoxide can be found to be low. The hyperdynamic circulation of cirrhosis can also arise in left atrial enlargement in the absence of any specific cardiac disease [78], although this has not been observed in all studies [64, 65]. Inclusively, right-sided cardiac dilatation was observed in one study [65]. Marked hypoxaemia during sleep has been described in HPS [79] and it is recommended to assess overnight pulse oximetry.

Most authorities consider arterial oxygen saturation measured by pulse oximetry $\left(\mathrm{Sp}_{\mathrm{p}} \mathrm{O}_{2}\right)$ to be not sufficiently accurate for identifying hypoxaemia in HPS: at an $\mathrm{Sp}_{\mathrm{p}} \mathrm{O}_{2}$ of $95 \%$ the $\mathrm{Pa}_{1} \mathrm{O}_{2}$ can differ by $>10 \mathrm{mmHg}$ among individuals with cirrhosis and, given the shape of the oxyhaemoglobin dissociation curve, small changes in $\mathrm{Sp}_{\mathrm{p}} \mathrm{O}_{2}$ are paralleled by large changes in $\mathrm{Pa}_{\mathrm{a}} \mathrm{O}_{2}$ $[29,80]$. This measurement can also be affected by deep breathing, smoking and methemoglobinaemia [81]. However, it can provide useful information for screening, as an $\mathrm{Sp}_{\mathrm{O}} \mathrm{O}_{2}$ $\geqslant 96 \%$ excludes a $\mathrm{Pa}_{\mathrm{a}} \mathrm{O}_{2}<70 \mathrm{mmHg}$ (sensitivity of $100 \%$,

\begin{tabular}{|c|c|c|}
\hline \multirow[t]{2}{*}{ TABLE 2} & \multicolumn{2}{|c|}{$\begin{array}{l}\text { Diagnostic criteria and staging for } \\
\text { hepatopulmonary syndrome }\end{array}$} \\
\hline & ${\mathrm{PA}-\mathrm{a}, \mathrm{O}_{2}}^{\#} \mathrm{mmHg}$ & $\mathrm{Pa}, \mathrm{O}_{2}^{\circ} \mathrm{mmHg}$ \\
\hline Mild & $\geqslant 15$ & $\geqslant 80$ \\
\hline Moderate & $\geqslant 15$ & $\geqslant 60$ to $<80$ \\
\hline Severe & $\geqslant 15$ & $\geqslant 50$ to $<60$ \\
\hline Very severe & $\geqslant 15$ & $<50$ \\
\hline
\end{tabular}

specificity of $88 \%$ ) [61], and given its non-invasiveness and extremely low cost, it is a cost-effective method that can be used for serial monitoring of oxygenation in patients with cirrhosis $[66,82]$.

Measurement of ABGs is the gold standard for identifying arterial deoxygenation and classifying HPS according to the degree of hypoxaemia. $\mathrm{Pa}_{\mathrm{a}_{2}}$ is the main prognostic determinant for HPS, although, because of the reflex hyperventilation (increased alveolar oxygen tension), it underestimates the oxygenation defect. Thus, $\mathrm{PA}-\mathrm{a}, \mathrm{O}_{2}$ is the most important parameter for the early diagnosis of HPS. The European Respiratory Society Task Force recommends a $P A-a, O_{2} \geqslant 15 \mathrm{mmHg}$ for the diagnosis of HPS, whereas $\mathrm{Pa}_{1} \mathrm{O}_{2}$ is used to classify the severity of HPS (table 2) [29]. However, using $\geqslant 20 \mathrm{mmHg}$ or the age-related threshold for HPS has been reported to improve the diagnostic accuracy of the $\mathrm{PA}-\mathrm{a}, \mathrm{O}_{2}$ (negative predictive values for $\geqslant 15 \mathrm{mmHg}, \geqslant 20 \mathrm{mmHg}$ and age-related $\mathrm{PA}-\mathrm{a}, \mathrm{O}_{2}$ threshold were $75 \%, 83 \%$ and $87 \%$, respectively) [68]. Using $\geqslant 15 \mathrm{mmHg}$ as a diagnostic criterion for HPS may result in a relatively high frequency of false positive diagnosis. Other causes for an enlarged $\mathrm{PA}-\mathrm{a}, \mathrm{O}_{2}$, such as hepatic hydrothorax, ascites and atelectasis, should be considered in the differential. Although there are several available formulas for calculating the age-related $\mathrm{PA}-\mathrm{a}, \mathrm{O}_{2}$ threshold, a popular formula is: normal $P A-a, \mathrm{O}_{2}=10+0.43$ (age-20).

ABGs are usually obtained while the patient is sitting and breathing room air, but two characteristic features linked to the pathophysiology of HPS can be also studied with ABGs. 1) Orthodeoxia, which manifests as a decrease in $\mathrm{Pa}_{1} \mathrm{O}_{2}$ of $\geqslant 4$ $\mathrm{mmHg}$ or $\geqslant 5 \%$ from the supine to the upright position [83], and 2) the increase in $\mathrm{Pa}_{1} \mathrm{O}_{2}$ while breathing $100 \%$ oxygen, which should reach $>300 \mathrm{mmHg}[29,35]$. Orthodeoxia is a consequence of the increased $V^{\prime} / Q^{\prime}$ mismatch and decreased cardiac output following the change from the supine to the upright position.

Contrast-enhanced TTE (CE-TTE) has become the most commonly used test for identifying the intravascular vasodilatation of HPS. Contrast is usually accomplished by injecting $10 \mathrm{~mL}$ of normal saline that has been hand-agitated, producing microbubbles ( $\leqslant 90 \mu \mathrm{m}$ in diameter). This opacifies the left atrium four or more beats after the initial appearance of contrast in the right atrium in patients with HPS, whereas those with a cardiac right-to-left shunt (i.e. atrial septal defect) 
will show opacification of the left atrium within the first three beats [84]. Trans-oesophageal echocardiogram (CE-TEE) is rarely needed, but because of an improved window it may increase the sensitivity of the test and help to better define dubious cases of inter-atrial communication. However, CETEE is more expensive, requires sedation and poses a low risk of complications with variceal bleeding. A recent report with a small number of patients proposed performing the CE-TTE in the upright position as another measure to increase the sensitivity of the test [64].

Lung perfusion scanning with macro-aggregated albumin (MAA scan) provides a quantitative assessment of the severity of the intrapulmonary vasodilatation. In this method the signal of ${ }^{99 \mathrm{~m}}$ Tc-radiolabelled MAA ( $>20 \mu \mathrm{m}$ in diameter) is abnormally detected outside of the lungs (in the brain by convention), as these particles should remained trapped within the lungs in the absence of intrapulmonary vasodilatation. A result of $>6 \%$ was observed in all HPS patients with a $\mathrm{Pa}, \mathrm{O}_{2}$ $<60 \mathrm{mmHg}$, and this cut-off value had a sensitivity of $84 \%$ and specificity of $100 \%$ for the diagnosis of HPS [85]. This study used a $\mathrm{Pa}_{\mathrm{a}} \mathrm{O}_{2}$ of $<70 \mathrm{mmHg}$ or a $\mathrm{PA}-\mathrm{a}, \mathrm{O}_{2}$ above the agecalculated normal and CE-TTE as the gold standard, and thus it is expected that with current diagnostic standards the rate of false negatives may be higher. Even though an MAA scan is not necessary for the diagnosis of HPS, it can help to identify clinically significant pulmonary vasodilatation, especially in patients with intrinsic lung disease in whom it is difficult to establish the contribution of HPS to hypoxaemia.

Pulmonary angiography is rarely needed but allows the classification of HPS as type I, with normal angiography or diffuse vascular dilatations (early or spidery, more advanced or spongy), or type II, characterised by discrete arteriovenous communications. The latter are anatomically stable and may not regress after LTx, causing post-transplant persistent hypoxaemia. Arteriovenous communications may be amenable to treatment with coil embolisation. It has been suggested that in patients with very severe hypoxaemia the response to $100 \%$ oxygen breathing should be assessed and if $\mathrm{Pa}_{1} \mathrm{O}_{2}$ improves to $<300 \mathrm{mmHg}$ an angiography should follow to rule out a possible type-II HPS (a contrasted lung computed tomography

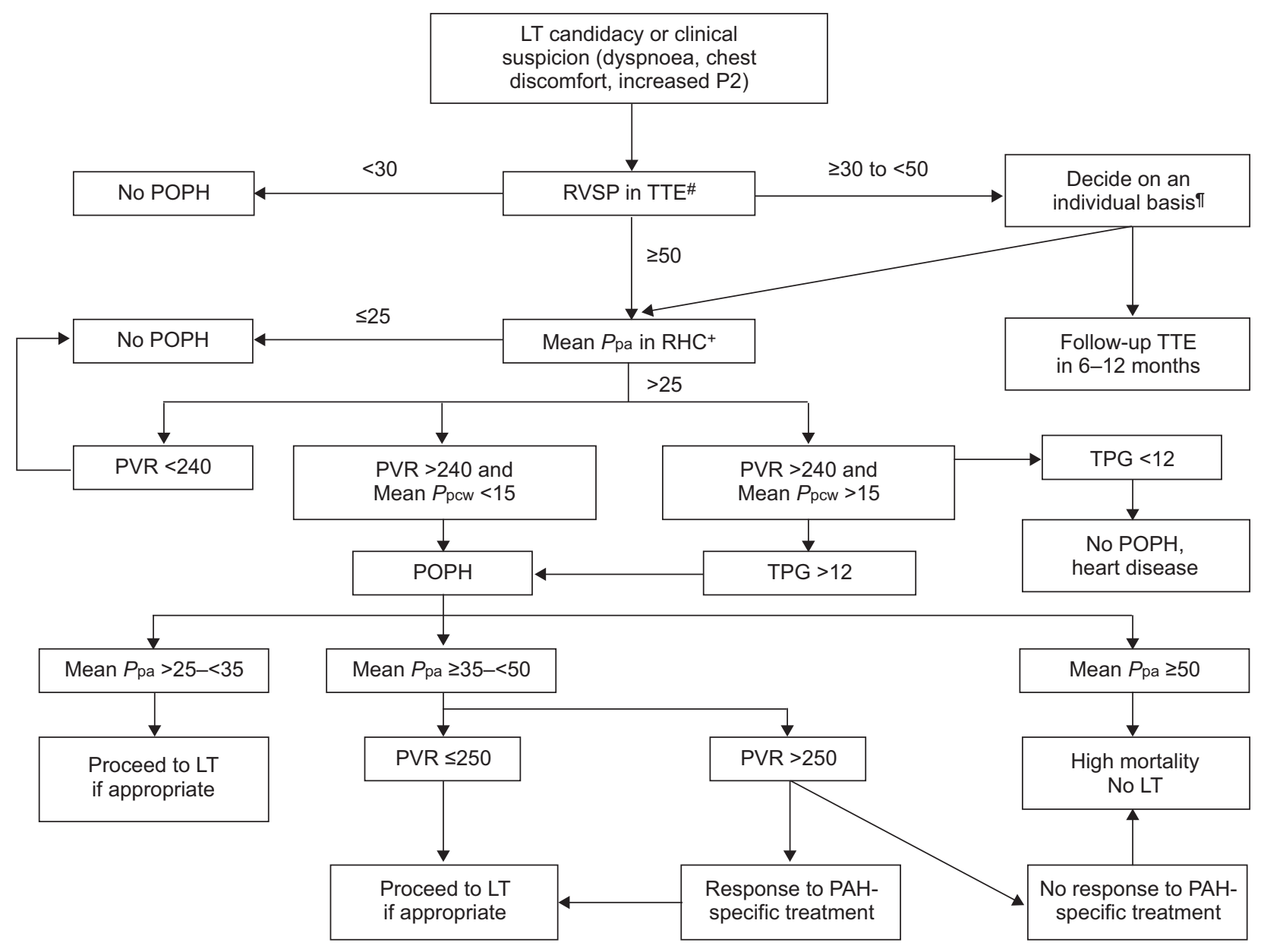

FIGURE 1. Algorithm for the diagnosis and treatment of portopulmonary hypertension (POPH). All pressure determinations are expressed in mmHg. LT: liver transplant; RHC: right heart catheterisation; RVSP: right ventricle systolic pressure; $P$ pa: pulmonary artery pressure; $P$ pcw: pulmonary capillary wedge pressure; PAH: pulmonary arterial hypertension; PVR: pulmonary vascular resistance; TPG: transpulmonary gradient; TTE: transthoracic echocardiogram. \#: Some centres report the pulmonary artery systolic pressure, which is equivalent to RVSP in the absence of right ventricle outflow obstruction; ": the presence of signs of right ventricular strain would favour performing RHC; ${ }^{+}$: alternative causes of pulmonary hypertension need to be ruled out on a case-by-case basis. 
scan may serve this purpose well). If this is confirmed, embolotherapy should be considered before LTx $[75,86]$.

\section{Prognosis and clinical course}

HPS is associated with attenuated quality of life and increased mortality, with hypoxaemia expected to progress even in the presence of stable liver function [59]. Mortality among patients with HPS at 2.5 yrs has been reported to be between 40 and $60 \%[60,65,87,88]$, with a prospective multicentre study observing mortality risk more than twice that of non-HPS patients after adjustment for MELD score and LTx (hazard ratio 2.41, 95\% CI 1.31-4.42) [65]. Apart from occasional mortality related to stroke, possibly from paradoxical embolism, there are no specific causes of death linked to HPS and mortality is related to progression of liver disease and portal hypertension-derived complications [60,65,88]. The degree of hypoxaemia within HPS cohorts has also been associated with a higher mortality, and it has been estimated that hypoxaemia progresses at a rate of $5 \mathrm{mmHg}$ per year [88]

In relation to quality of life, it was shown that HPS affects the sense of general health, particularly in the domains associated with the mental component of short form-36 [65]. It is plausible that hypoxaemia could affect cognition and contribute as a risk factor for hepatic encephalopathy, and one study identified a higher frequency of asterixis in HPS versus non-HPS cirrhotics [65]. Coexistence of hepatic encephalopathy would further compromise the prognosis of patients with HPS.

\section{Treatment}

LTx is the only definitive therapy, with improvement of arterial deoxygenation and intrapulmonary dilatation occurring almost universally post-transplant. The rate of improvement in $\mathrm{Pa}, \mathrm{O}_{2}$ is variable, probably occurring months to years after LTx, varying with severity of hypoxaemia before LTx. Post-transplant improvement in HPS is paralleled by normalisation of the ${ }^{99 \mathrm{~m}} \mathrm{TcMAA}$ shunt scan [88]. In general, the abnormalities of HPS resolve in $>85 \%$ of patients within the first 6-12 months post-transplant [89]. Lack of improvement should prompt consideration of discrete arteriovenous anastomoses or pulmonary vascular remodelling. Because of the impaired prognosis of HPS and favourable outcome after LTx, MELD exception points are given to patients with severe hypoxaemia in the USA so as to expedite LTx [90].

Analysis of the Scientific Registry for Transplant Recipients found that post-transplant survival for patients with HPS patients is comparable to that of patients without HPS [77]. Nonetheless, some pre-LTx characteristics predict an increased mortality after LTx, such as hypoxaemia $\leqslant 50 \mathrm{mmHg}$ and a ${ }^{99 m}$ TcMAA shunt scan $\geqslant 20 \%[88,89]$.

Several studies have addressed the therapeutic potential of compounds affecting the mechanisms involved in the pathogenesis of HPS. Overall, results have not been promising. Supplemental oxygen remains the only proven effective therapy and it should be administered when the $\mathrm{Pa}, \mathrm{O}_{2}$ reaches

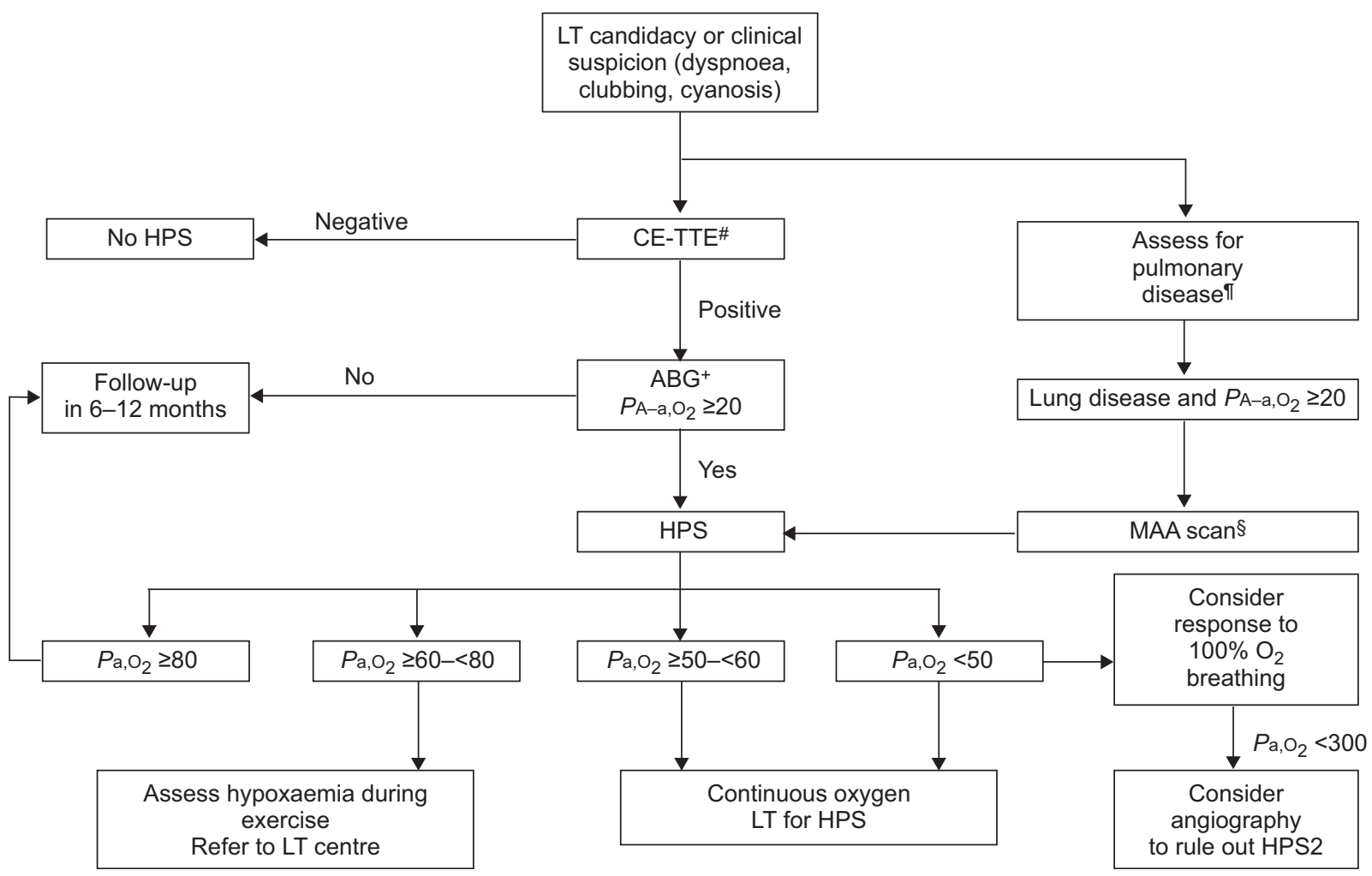

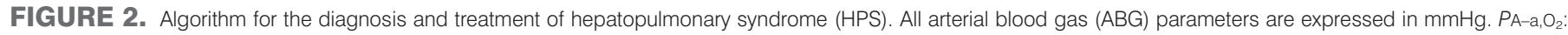

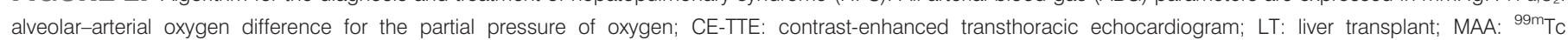

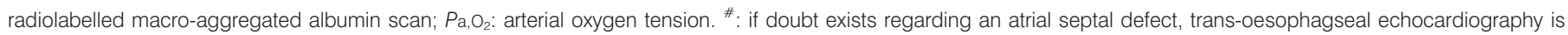

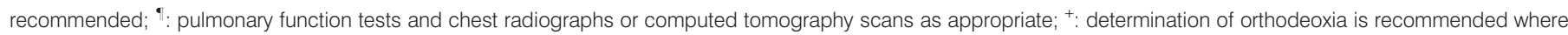
available; ${ }^{\S}$ : MAA is also useful in the absence of lung disease to quantify the intrapulmonary shunt and for prognostication. 
$<60 \mathrm{mmHg}$. Transjugular intrahepatic portosystemic shunt should not be considered a therapeutic option for HPS. Two pilot studies of somatostatin analogues observed no changes in oxygenation parameters [87, 91]. Inhibitors of NO, such as methylene blue and L-NAME ( $\mathrm{N}^{\mathrm{G}}$-nitro-L-arginine methyl ester) have also been tested. Methylene blue inhibits the cyclic guanosine monophosphate pathway that is responsible for NO production. In seven patients, a single dose of intravenous methylene blue improved both the $\mathrm{Pa}, \mathrm{O}_{2}$ and $\mathrm{PA}-\mathrm{a}, \mathrm{O}_{2}$, as well as the hyperdynamic circulation and increased the PVR for a few hours after its administration [92]. Nebulised L-NAME was tested in 10 patients with HPS and although it decreased exhaled NO, improved the hyperdynamic circulation, and increased the pulmonary vascular resistance, it failed to improve the $V^{\prime} / Q^{\prime}$ mismatch, $\mathrm{Pa}_{1} \mathrm{O}_{2}$ or $\mathrm{PA}-\mathrm{a}, \mathrm{O}_{2}$ after $2 \mathrm{~h}$ of administration [93]. Garlic is thought to exert vasodilatory properties that may redistribute the pulmonary blood flow, improving the $V^{\prime} / Q^{\prime}$ mismatch. Apart from a positive pilot study [94], a randomised, double-blind, controlled trial showed that two thirds of patients using garlic oil capsules $(n=21)$ had resolution of HPS after 9 months of treatment, in comparison to only one patient in the placebo group $(n=20)$ [95]. Although these results are encouraging, they will need to be replicated by other groups before reaching any definitive conclusions regarding the use of garlic in HPS. Of note, the placebo group showed an increase in $\mathrm{Pa}_{1} \mathrm{O}_{2}$ of $5 \mathrm{mmHg}$ after $1 \mathrm{yr}$ of follow-up, contrasting with the expected decrease of the same magnitude.

Other medications have been tested with the aim of reducing the endotoxaemia and/or associated proinflammatory response (e.g. tumour necrosis factor- $\alpha$ ), in order to improve the intrapulmonary dilatation and oxygenation. An open-label, singlearm clinical trial failed to show any improvement in $\mathrm{Pa}_{2} \mathrm{O}_{2}$ or $\mathrm{PA}-$ $\mathrm{a}_{1} \mathrm{O}_{2}$ after 6 weeks of pentoxifylline. However, the study included only nine patients and not all of them were able to fulfil the intended follow-up or adherence to therapy, mostly due to adverse effects of pentoxifylline [96]. More recently, a blinded randomised crossover study did not show any benefit in $\mathrm{PA}-\mathrm{a}, \mathrm{O}_{2}$ after 4 weeks of norfloxacin, as compared with placebo [97].

\section{CONCLUSIONS}

Liver disease and portal hypertension are associated with dyspnoea and hypoxaemia by various mechanisms, with the pulmonary vascular complications conferring the greatest impact on prognosis. POPH and HPS are relatively common among LTx candidates; POPH is reported in 6-9\% and HPS in $10-30 \%$ of LTx candidates. HPS and POPH should be sought routinely as part of the evaluation of patients being considered for LTx as most cases are either asymptomatic or present with nonspecific symptoms. Diagnostic criteria for POPH include two proposed cut-off values for PVR (120 and $\left.240 \mathrm{dyn} \cdot \mathrm{s} \cdot \mathrm{cm}^{-5}\right)$. Diagnostic criteria for HPS include an elevated $\mathrm{PA}-\mathrm{a}, \mathrm{O}_{2}$ of $\geqslant 15$ or $\geqslant 20 \mathrm{mmHg}$, or age-related normal. Awareness of POPH and HPS and familiarity with the approach to diagnostic work-up and available therapies are critical in achieving optimal healthrelated quality of life and survival in patients with $\mathrm{POPH}$ and HPS. Although both diseases may improve after LTx, the severest forms of POPH are a contraindication to LTx. LTx should be considered as a definitive therapy for all but the most severe forms of HPS. Novel therapeutic approaches for POPH are evolving, with emerging evidence that PAH-specific drugs can expand the pool of transplantable patients and improve survival. It must be acknowledged that LTx seeks to improve portal hypertension and liver disease in $\mathrm{POPH}$ patients, but the latter may persist or even progress after LTx. On the basis of available evidence we have built diagnostic/therapeutic algorithms to be used both by pulmonologists and hepatologists caring for LTx candidates (figs 1 and 2). These are based on current LTx protocols at the Mayo Clinic and recommendations from the European Respiratory Society, and have proved to be useful in the LTx clinical setting. In the USA, MELD exception points can be granted to some moderate forms of POPH and to the severe forms of HPS so as to prioritise LTx and favour the reversal of pulmonary vascular complications.

\section{STATEMENT OF INTEREST}

None declared.

\section{REFERENCES}

1 Porres-Aguilar M, Zuckerman MJ, Figueroa-Casas JB, et al. Portopulmonary hypertension: state of the art. Ann Hepatol 2008; 7: $321-330$

2 Golbin JM, Krowka MJ. Portopulmonary hypertension. Clin Chest Med 2007; 28: 203-218.

3 Savale L, O'Callaghan DS, Magnier R, et al. Current management approaches to portopulmonary hypertension. Int J Clin Pract Suppl 2011; 169: 11-18.

4 Simonneau G, Robbins IM, Beghetti M, et al. Updated clinical classification of pulmonary hypertension. J Am Coll Cardiol 2009; 54: Suppl. 1, S43-S54.

5 Porres-Aguilar M. Emphasizing the importance of the clinical classification for pulmonary hypertension. Ann Hepatol 2009; 8: 267-268.

6 McDonnell PJ, Toye PA, Hutchins GM. Primary pulmonary hypertension and cirrhosis: are they related? Am Rev Respir Dis 1983; 127: 437-441.

7 Kawut SM, Krowka MJ, Trotter JF, et al. Clinical risk factors for portopulmonary hypertension. Hepatology 2008; 48: 196-203.

8 Ramsay MA, Simpson BR, Nguyen AT, et al. Severe pulmonary hypertension in liver transplant candidates. Liver Transpl Surg 1997; 3: 494-500.

9 Krowka MJ, Swanson KL, Frantz RP, et al. Portopulmonary hypertension: results from a 10-year screening algorithm. Hepatology 2006; 44: 1502-1510.

10 Benza RL, Miller DP, Gomberg-Maitland M, et al. Predicting survival in pulmonary arterial hypertension: insights from the registry to evaluate early and long-term pulmonary arterial hypertension disease management (REVEAL). Circulation 2010; 122: 164-172.

11 Farber HW, Loscalzo J. Pulmonary arterial hypertension. N Engl J Med 2004; 351: 1655-1665.

12 Hervé $\mathrm{P}$, Lebrec $\mathrm{D}$, Brenot $\mathrm{F}$, et al. Pulmonary vascular disorders in portal hypertension. Eur Respir J 1998; 11: 1153-1166.

13 Benjaminov FS, Prentice M, Sniderman KW, et al. Portopulmonary hypertension in decompensated cirrhosis with refractory ascites. Gut 2003; 52: 1355-1362.

14 Neuhofer W, Gülberg V, Gerbes AL. Endothelin and endothelin receptor antagonism in portopulmonary hypertension. Eur J Clin Invest 2006; 36: Suppl. 3, 54-61.

15 Kéreveur A, Callebert J, Humbert M, et al. High plasma serotonin levels in primary pulmonary hypertension. Effect of long-term epoprostenol (prostacyclin) therapy. Arterioscler Thromb Vasc Biol 2000; 20: 2233-2239. 
16 Hervé P, Launay JM, Scrobohaci ML, et al. Increased plasma serotonin in primary pulmonary hypertension. Am J Med 1995; 99 : 249-254.

17 Roberts KE, Fallon MB, Krowka MJ, et al. Serotonin transporter polymorphisms in patients with portopulmonary hypertension. Chest 2009; 135: 1470-1475.

18 Roberts KE, Fallon MB, Krowka MJ, et al. Genetic risk factors for portopulmonary hypertension in patients with advanced liver disease. Am J Respir Crit Care Med 2009; 179: 835-842.

19 Tuder RM, Cool CD, Geraci MW, et al. Prostacyclin synthase expression is decreased in lungs from patients with severe pulmonary hypertension. Am J Respir Crit Care Med 1999; 159: 1925-1932.

20 Huffmyer JL, Nemergut EC. Respiratory dysfunction and pulmonary disease in cirrhosis and other hepatic disorders. Respir Care 2007; 52: 1030-1036.

21 Moller S, Henriksen JH. Cardiopulmonary complications in chronic liver disease. World J Gastroenterol 2006; 12: 526-538.

22 Kuo PC, Plotkin JS, Gaine S, et al. Portopulmonary hypertension and the liver transplant candidate. Transplantation 1999; 67: 1087-1093.

23 Swanson KL, Krowka MJ. Arterial oxygenation associated with portopulmonary hypertension. Chest 2002; 121: 1869-1875.

24 Colle IO, Moreau R., Godinho E, et al. Diagnosis of portopulmonary hypertension in candidates for liver transplantation: a prospective study. Hepatology 2003; 37: 401-409.

25 Murray KF, Carithers RL. AASLD practice guidelines: evaluation of the patient for liver transplantation. Hepatology 2005; 41: 1407-1432.

26 Galiè N, Hoeper MM, Humbert M, et al. Guidelines for the diagnosis and treatment of pulmonary hypertension: the Task Force for the Diagnosis and Treatment of Pulmonary Hypertension of the European Society of Cardiology (ESC) and the European Respiratory Society (ERS), endorsed by the International Society of Heart and Lung Transplantation (ISHLT). Eur Heart J 2009; 30: 2493-2537.

27 Krowka MJ. Portopulmonary hypertension: diagnostic advances and caveats. Liver Transpl 2003; 9: 1336-1337.

28 Kim WR, Krowka MJ, Plevak DJ, et al. Accuracy of Doppler echocardiography in the assessment of pulmonary hypertension in liver transplant candidates. Liver Transpl 2000; 6: 453-458.

29 Rodríguez-Roisin R, Krowka MJ, Hervé P, et al. PulmonaryHepatic vascular Disorders (PHD). Eur Respir J 2004; 24: 861-880.

30 Swanson KL, Krowka MJ. Screen for portopulmonary hypertension, especially in liver transplant candidates. Cleve Clin J Med 2008; 75: 121-136.

31 Robalino BD, Moodey DS. Association between primary pulmonary hypertension and portal hypertension: analysis of its pathophysiology and clinical, laboratory, and hemodynamic manifestations. J Am Coll Cardiol 1991; 17: 492-498.

32 Le Pavec J, Souza R, Herve P, et al. Portopulmonary hypertension: survival and prognostic factors. Am J Respir Crit Care Med 2008; 178: 637-643.

33 Swanson K, Wiesner R, Nyberg S, et al. Survival in portopulmonary hypertension: Mayo Clinic experience categorized by treatment subgroups. Am J Transplant 2008; 8: 2445-2453.

34 Sitbon $\mathrm{O}$, Humbert $\mathrm{M}$, Jaïs $\mathrm{X}$, et al. Long-term response to calcium channel blockers in idiopathic pulmonary arterial hypertension. Circulation 2005; 111: 3105-3111.

35 Montani D, Savale L, Natali D, et al. Long-term response to calcium channel blockers in non-idiopathic pulmonary arterial hypertension. Eur Heart J 2010; 31: 1898-1907.

36 Ota K, Shijo H, Kokawa H, et al. Effects of nifedipine on hepatic venous pressure gradient and portal vein blood flow in patients with cirrhosis. J Gastroenterol Hepatol 1995; 10: 198-204.

37 Provencher S, Herve P, Jais X, et al. Deleterious effects of betablockers on exercise capacity and hemodynamics in patients with portopulmonary hypertension. Gastroenterology 2006; 130: 120-126.
38 Vera-Lastra O, Porres-Aguilar M. Pulmonary arterial hypertension associated with systemic sclerosis: current diagnostic approach and therapeutic strategies. World J Rheumatol 2012; (In press).

39 Krowka MJ, Frantz RP, McGoon MD, et al. Improvement in pulmonary hemodynamics during intravenous epoprostenol (prostacyclin): a study of 15 patients with moderate to severe portopulmonary hypertension. Hepatology 1999; 30: 641-648.

40 Sussman N, Kaza V, Barshes N, et al. Successful liver transplantation following medical management of portopulmonary hypertension: a single-center series. Am J Transpl 2006; 6: 2177-2182.

41 Fix OK, Bass NM, De Marco T, et al. Long-term follow-up of portopulmonary hypertension: effect of treatment with epoprostenol. Liver Transpl 2007; 13: 875-885.

42 Halank M, Marx C, Usicenko S, et al. Inhaled iloprost for patients with portopulmonary hypertension. Am J Respir Crit Care Med 2003; A277.

43 Minder S, Fischler M, Muellhaupt B, et al. Intravenous iloprost bridging to orthotopic liver transplantation in portopulmonary hypertension. Eur Respir J 2004; 24: 703-707.

44 Melgosa MT, Ricci GL, García-Pagan JC, et al. Acute and long-term effects of inhaled iloprost in portopulmonary hypertension. Liver Transpl 2010; 16: 348-356.

45 Hoeper MM, Halank M, Marx C, et al. Bosentan therapy for portopulmonary hypertension. Eur Respir J 2005; 25: 502-508.

46 Cartin-Ceba R, Swanson K, Iyer V, et al. Safety and efficacy of ambrisentan for the treatment of portopulmonary hypertension. Chest 2011; 139: 109-114.

47 Galiè N, Ghofrani HA, Torbicki A, et al. Sildenafil citrate therapy for pulmonary arterial hypertension. $N$ Engl J Med 2005; 353: 2148-2157.

48 Galiè N, Brundage BH, Ghofrani HA, et al. Tadalafil therapy for pulmonary arterial hypertension. Circulation 2009; 119: 2894-2903.

49 Reichenberger F, Voswinckel R, Steveling E, et al. Sildenafil treatment for portopulmonary hypertension. Eur Respir J 2006; 28: 563-567.

50 Krowka MJ, Swanson KL. How should we treat portopulmonary hypertension? Eur Respir J 2006; 28: 466-467.

51 Krowka MJ, Mandell MS, Ramsay MA, et al. Hepatopulmonary syndrome and portopulmonary hypertension: a report of the multicenter liver transplant database. Liver Transpl 2004; 10: 174-182.

52 Krowka MJ, Plevak DJ, Findlay JY, et al. Pulmonary hemodynamics and perioperative cardiopulmonary-related mortality in patients with portopulmonary hypertension undergoing liver transplantation. Liver Transplant 2000; 6: 443-450.

53 Krowka MJ, Fallon MB, Mulligan DC, et al. Model for end-stage pulmonary disease (MELD) exception in for portopulmonary hypertension. Liver Transpl 2006; 12: Suppl. 3, S114-S116.

54 Ashfaq M, Chinnakotla S, Rogers L, et al. The impact of treatment of portopulmonary hypertension on survival following liver transplantation. Am J Transpl 2007; 7: 1258-1264.eHeal.

55 Raval Z, Harinstein ME, Skaro AI, et al. Cardiovascular risk assessment of the liver transplant candidate. J Am Coll Cardiol 2011; 58: 223-231.

56 Bandara M, Gordon FD, Sarwar A, et al. Successful outcomes following living donor liver transplantation for portopulmonary hypertension. Liver Transpl 2010; 16: 983-989.

57 Rafanan AL, Maurer J, Mehta AC, et al. Progressive portopulmonary hypertension after liver tranplasntation treated with epoprostenol. Chest 2000; 118: 1497-1500.

58 Rodriguez-Roisin R, Krowka MJ. Hepatopulmonary syndrome - a liver-induced lung vascular disorder. N Engl J Med 2008; 29: 2378-2387.

59 Krowka MJ, Porayko MK, Plevak DJ, et al. Hepatopulmonary syndrome with progressive hypoxemia as an indication for liver transplantation: case reports and literature review. Mayo Clin Proc 1997; 72: 44-53. 
60 Schenk P, Schöniger-Hekele M, Fuhrmann V, et al. Prognostic significance of the hepatopulmonary syndrome in patients with cirrhosis. Gastroenterology 2003; 125: 1042-1052.

61 Arguedas MR, Singh H, Faulk DK, et al. Utility of pulse oximetry screening for hepatopulmonary syndrome. Clin Gastroenterol Hepatol 2007; 5: 749-754.

62 Deibert P, Allgaier HP, Loesch S, et al. Hepatopulmonary syndrome in patients with chronic liver disease: role of pulse oximetry. BMC Gastroenterol 2006; 6: 15 .

63 Santa-Cruz RA, Pearson MD, Cohen MG, et al. Clinical predictors and characteristics of patients with chronic liver disease and intrapulmonary shunts. Clin Cardiol 2005; 28: 437-441.

64 Lenci I, Alvior A, Manzia TM, et al. Saline contrast echocardiography in patients with hepatopulmonary syndrome awaiting liver transplantation. J Am Soc Echocardiogr 2009; 22: 89-94.

65 Fallon MB, Krowka MJ, Brown RS, et al. Impact of hepatopulmonary syndrome on quality of life and survival in liver transplant candidates. Gastroenterology 2008; 135: 1168-1175.

66 Kochar R, Nevah Rubin MI, Fallon MB. Pulmonary complications of cirrhosis. Curr Gastroenterol Rep 2011; 13: 34-39.

67 Vachiéry F, Moreau R, Hadengue A, et al. Hypoxemia in patients with cirrhosis: relationship with liver failure and hemodynamic alterations. J Hepatol 1997; 27: 492-495.

68 Schenk P, Fuhrmann V, Madl C, et al. Hepatopulmonary syndrome: prevalence and predictive value of various cut offs for arterial oxygenation and their clinical consequences. Gut 2002; 51: 853-859.

69 Rodríguez-Roisin R, Agustí AG, Roca J. The hepatopulmonary syndrome: new name, old complexities. Thorax 1992; 47: 897-902.

70 Nunes H, Lebrec D, Mazmanian M, et al. Role of nitric oxide in hepatopulmonary syndrome in cirrhotic rats. Am J Respir Crit Care Med 2001; 164: 879-885.

71 Rabiller A, Nunes $H$, Lebrec D, et al. Prevention of Gram-negative translocation reduces the severity of hepatopulmonary syndrome. Am J Respir Crit Care Med 2002; 166: 514-517.

72 Thenappan T, Goel A, Marsboom G, et al. A central role for CD68 macrophages in hepatopulmonary syndrome. Reversal by macrophage depletion. Am J Respir Crit Care Med 2011; 183: 1080-1091.

73 Roberts KE, Kawut SM, Krowka MJ, et al. Genetic risk factors for hepatopulmonary syndrome in patients with advanced liver disease. Gastroenterology 2010; 139: 130-139.

74 Zhang J, Luo B, Tang L, et al. Pulmonary angiogenesis in a rat model of hepatopulmonary syndrome. Gastroenterology 2009; 136: 1070-1080.

75 Krowka MJ, Wiseman GA, Burnett OL, et al. Hepatopulmonary syndrome: a prospective study of relationships between severity of liver disease, $\mathrm{Pa}, \mathrm{O}_{2}$ response to $100 \%$ oxygen, and brain uptake after ${ }^{99} \mathrm{~m}_{\mathrm{T}} \mathrm{MAA}$ lung scanning. Chest 2000; 118: 615-624.

76 Koksal D, Kacar S, Koksal AS, et al. Evaluation of intrapulmonary vascular dilatations with high-resolution computed thorax thomography in patients with hepatopulmonary syndrome. J Clin Gastroenterol 2002; 40: 77-83.

77 Sulieman BM, Hunsicker LG, Katz DA, et al. OPTN policy regarding prioritization of patients with hepatopulmonary syndrome: does it provide equitable organ allocation? Am J Transplant 2008; 8: 954-964.

78 Zamirian M, Aslani A, Shahrzad S. Left atrial volume: a novel predictor of hepatopulmonary syndrome. Am J Gastroenterol 2007; 102: 1392-1396.
79 Palma DT, Philips GM, Arguedas MR, et al. Oxygen desaturation during sleep in hepatopulmonary syndrome. Hepatology 2008; 47: 1257-1263.

80 Clerbaux T, Detry B, Geubel A, et al. The oxyhemoglobin dissociation curve in liver cirrhosis. Chest 2006; 129: 438-445.

81 Krowka MJ. Hepatopulmonary syndrome: monitoring at your fingertip. Dig Dis Sci 2011; 56: 1599-1600.

82 Roberts DN, Arguedas MR, Fallon MB. Cost-effectiveness of screening for hepatopulmonary syndrome in liver transplant candidates. Liver Transpl 2007; 13: 206-214.

83 Gómez FP, Martínez-Pallí G, Barberà JA, et al. Gas exchange mechanism of orthodeoxia in hepatopulmonary syndrome. Hepatology 2004; 40: 660-666.

84 Abrams GA, Jaffe CC, Hoffer PB, et al. Diagnostic utility of contrast echocardiography and lung perfusion scan in patients with hepatopulmonary syndrome. Gastroenterology 1995; 109: 1283-1288.

85 Abrams GA, Nanda NC, Dubovsky EV, et al. Use of macroaggregated albumin lung perfusion scan to diagnose hepatopulmonary syndrome: a new approach. Gastroenterology 1998; 114: 305-310.

86 Poterucha JJ, Krowka MJ, Dickson ER, et al. Failure of hepatopulmonary syndrome to resolve after liver transplantation and successful treatment with embolotherapy. Hepatology 1995; 21: 96-100.

87 Krowka MJ, Dickson ER, Cortese DA. Hepatopulmonary syndrome. Clinical observations and lack of therapeutic response to somatostatin analogue. Chest 1993; 104: 515-521.

88 Swanson KL, Wiesner RH, Krowka MJ. Natural history of hepatopulmonary syndrome: Impact of liver transplantation. Hepatology 2005; 41: 1122-1129.

89 Arguedas MR, Abrams GA, Krowka MJ, et al. Prospective evaluation of outcomes and predictors of mortality in patients with hepatopulmonary syndrome undergoing liver transplantation. Hepatology 2003; 37: 192-197.

90 Fallon MB, Mulligan DC, Gish RG, et al. Model for end-stage liver disease (MELD) exception for hepatopulmonary syndrome. Liver Transp 2006; 12: Suppl. 3, S105-S107.

91 Söderman C, Juhlin-Dannfelt A, Lagerstrand L, et al. Ventilationperfusion relationships and central haemodynamics in patients with cirrhosis. Effects of a somatostatin analogue. J Hepatol 1994; 21: 52-57.

92 Schenk P, Madl C, Rezaie-Majd S, et al. Methylene blue improves the hepatopulmonary syndrome. Ann Intern Med 2000; 133: 701-706.

93 Gómez FP, Barberà JA, Roca J, et al. Effects of nebulized N ${ }^{\mathrm{G}}$ nitro-L-arginine methyl ester in patients with hepatopulmonary syndrome. Hepatology 2006; 43: 1084-1091.

94 Abrams GA, Fallon MB. Treatment of hepatopulmonary syndrome with Allium sativum L. (garlic): a pilot trial. I Clin Gastroenterol 1998; 27: 232-235.

95 De BK, Dutta D, Pal SK, et al. The role of garlic in hepatopulmonary syndrome: a randomized controlled trial. Can J Gastroenterol 2010; 24: 183-188.

96 Tanikella R, Philips GM, Faulk DK, et al. Pilot study of pentoxifylline in hepatopulmonary syndrome. Liver Transpl 2008; 14: 1199-1203.

97 Gupta S, Faughnan ME, Lilly L, et al. Norfloxacin therapy for hepatopulmonary syndrome: a pilot randomized controlled trial. Clin Gastroenterol Hepatol 2010; 8: 1095-1098. 